\title{
Apprehending attitudes and actions: Separable abilities in early development?
}

\author{
R. PETER HOBSON \\ Tavistock Clinic and UCL Medical School, London
}

\begin{abstract}
In this article, I explore whether there might be two separable components to person-perception and interpersonal engagement in infancy: the ability to apprehend other people's attitudes on the one hand, and the ability to perceive actions on the other. In support of this approach, I summarize some evidence from a recent study of autistic adolescents' judgments of attitudes and actions manifest in moving point-light displays of people. I highlight the far-reaching cognitive as well as social-developmental implications of early interpersonal-affective engagement. I conclude by speculating that certain abnormalities that would stem from autistic individuals' impaired ability to perceive and engage with people's attitudes may be somewhat mitigated by their relative ability to perceive the actions of others.
\end{abstract}

In this theoretical article, I discuss how a normal infant's capacity to perceive and respond to other people's emotional attitudes plays a vital role in early social and cognitive development. I illustrate how it is in the domain of developmental psychopathology, specifically through the study of early childhood autism, that we may find evidence pointing to the special quality and developmental significance of interpersonalaffective perception and relatedness.

One of the difficulties in approaching these matters, is clarifying terms such as "emotional attitudes" or "cognitive development." Part of the problem is that the meanings of these words may change radically when applied to different stages in development. For example, the contrasts between affect and cognition may be useful when applied to adult psychology, yet may

I am indebted to my colleagues Derek Moore and Tony Lee for their collaboration in the empirical study I have described in this paper, and to Mike Tomasello for lively discussions on a number of topics, not least the significance of predication.

Address correspondence and reprint requests to: $R$. Peter Hobson, Tavistock Clinic, 120 Belsize Lane, London, NW3 5BA, UK. prove misleading when characterizing the nature of psychological functioning in early childhood. On the other hand, it does not get us very far to pay lip-service to the inseparability of affect and cognition in infancy, if we fail to provide some alternative and more appropriate concepts to partition out the separable components of infant psychology. Such concepts should enable us to see how in due course, thinking, feeling, and so on emerge in their familiar adult guises.

In the past, I have dwelt upon the very young child's increasingly sophisticated awareness of "persons" as a major socialcognitive developmental achievement that yields the older child's concepts of "bodies" and "minds" (e.g., Hobson 1989; 1990c; 1991). In this article, I pursue a related but rather different thesis, that in shaping an account of early cognitive as well as social development, we should adopt a frame of reference couched in terms of an infant's ability to perceive, respond to, and identify with the subjectively experienced and emotionally toned attitudes of other people. I take my text from Lev Vygotsky (1962), who when reflecting on the nature of think- 
ing wrote that "every idea contains a transmuted affective attitude toward the bit of reality to which it refers" (p. 8). This statement not only captures something about what it means to think (and, incidentally, enables us to escape from the dead-end of methodological solipsism as espoused by Fodor, 1980), but it also points us toward an account of how thinking develops through the human capacity to have and to share attitudes toward the world.

To begin with, I review a highly selective series of observations on normal infancy. I draw a distinction between two facets of this development which are often conflated: the child's abilities to perceive, respond to, imitate, and identify with other people's actions on the one hand, and the child's ability to perceive, respond to, imitate, and identify with other people's attitudes on the other. I suggest that there are separable components to these aspects of interpersonal perception and engagement, and I highlight the significance of the "attitude" component for our account of early cognitive development. I also consider how the study of early childhood autism may inform our perspective on these matters.

\section{On Normal Early Development}

There is evidence that from very early in life, an infant perceives the presence and behavior of other people as significant and meaningful. Consider an infant's responsiveness to another person's actions. One oft-cited phenomenon in this respect is that of neonatal imitation (e.g., Meltzoff, 1990; Meltzoff \& Moore, 1977). For example, Meltzoff and Moore (1983) confronted newborns with someone demonstrating mouth opening and tongue protrusion, and arranged for an observer who was blind to the modeled behavior to judge the infants' videotaped responses. There were significantly more infant mouth openings in responses to the mouth display than to the tongue display, and more tongue protrusions to the tongue display (see Meltzoff \& Moore, 1989 , for a study with infants who also matched head movements). Corrobo- rating evidence for such interpersonal coordination can be gleaned from observations of the mutual patterning of adult-infant interactions in more natural circumstances, although as in the case of neonatal imitation, young infants' attentiveness and responsiveness to the movements and actions of other people have been subject to alternative interpretations (e.g., Brazelton, Koslowski, \& Main, 1974; Frye, Rawling, Moore, \& Myers, 1983; Kaye, 1982; Stern, 1977; Sylvester-Bradley, 1985; Trevarthen, 1979). The dramatic effects on 3-montholds of "perturbations" in the mutuality of caregiver-infant exchanges induced, for example, by adults adopting a "still face" (Cohn \& Tronick, 1983) or by experimenters introducing feedback delays in TVlinked mother-infant transactions (Murray \& Trevarthen, 1985), strongly suggest that young infants do perceive and react to adults' behavior toward themselves. Moreover in experimental studies of young infants' perceptual abilities, 3- to 5-montholds have demonstrated attentiveness to point-light displays of a walking person represented only as moving dots of light attached to the person's body and limbs, in preference to other randomly moving pointlights or upside-down point-light people (e.g., Bertenthal, Proffitt \& Cutting, 1984; Fox \& McDaniel, 1982). This suggests that quite young infants are able to pick up ecologically significant information from the biomechanical motion of the bodies of other people.

Note that in such studies, there is often ambiguity over the kinds of person-related meaning that may be salient and discriminable to young infants. To return to neonatal imitation, for example, infants less than 2 days-old have been presented with posed emotional expressions as well as actions (Field, 1985; Field et al., 1983; Field, Woodson, Greenberg, \& Cohen, 1982). The infants were reported to show widened eyes and mouth opening in response to a model's surprised face, lip widening to a happy face, and tightened mouth with protruding lips accompanied by a furrowed brow to a sad expression. Is this mimicking of "behav- 
ior," or does it involve the perception of feelings? Or again, in the aforementioned observations of natural and perturbed adult-infant interactions, what importance should be assigned to an infant's perception of and responsiveness to an adult's emotional expressions? For that matter, how much in the form and timing of behavior is to count as "emotional"? Here it is relevant that infants have been found to respond emotionally not only to disembodied vocal expressions of feeling (Sagi \& Hoffman, 1976; Simner, 1971), but also to another person's whole-body expressions. Haviland and Lelwica (1987) asked the mothers of 10week-old infants to enact a range of affective states in their facial and vocal expressions during face-to-face exchanges with their babies, and the infants reacted to each of the presentations with affective states of their own. These reactions were manifest not only in the infants' facial and other bodily gestures, but also in patterns of gaze that were not presented by the mothers. So too, in more contrived experiments on social perception, infants 5-7 months-of-age have been reported to demonstrate selective attention to emotional information that is invariant across vocal and visual presentations of given affective expressions (Walker, 1982), as well as to discriminate between dynamic face-voice expressions shown on videotape and among more static, photographed facial expressions (Caron, Caron, \& Myers, 1982; La Barbera, Izard, Vietze, \& Parisi, 1976; Young-Browne, Rosenfeld, \& Horowitz, 1977). We are led to reflect on what is essentially "emotional" in such discriminative abilities and to consider the relation between infants' capacities for "action recognition" and "affect recognition."

My purpose in citing these observations and experiments is to highlight an issue that is sometimes glossed over or neglected in accounts of early development: whether an infant's capacity to perceive and react to other people's actions is partly separable from the infant's capacity to perceive and react to other people's attitudes. This kind of distinction has received more attention re- garding observations on infants 9-12 months-of-age, for here there is the widely recognized contrast between protoimperative and protodeclarative communicative functions (Bates, 1979; Bates, Benigni, Bretherton, Camaioni, \& Volterra, 1979; Bates, Camaioni, \& Volterra, 1975; Camaioni, 1992). Protoimperatives are communicative acts such as requesting, which are intended to induce someone else to do something; protodeclarative are acts such as indicating or showing things, intended to share experiences with (and/or engage the attitudes of) someone else. Even here, however, where protodeclarative communication is often characterized as a matter of the infant engaging someone else's "attention," theoretical work on precursors to such intersubjective engagement has been rather piecemeal. I shall return to this matter shortly, but I emphasize how the range of new accomplishments that emerge late in the first year is made up of propensities and abilities that might be considered more or less heavily weighted in their "action" and "attitude" components. The list includes the infant's capacity to follow the eye gaze or point of another person, to request actions and to respond to simple verbal requests by others, to indicate or show objects to others (often looking to the other person's eyes, to check whether he or she is attending), to initiate as well as accept invitations to games such as peek-a-boo, to shake the head to express refusal, to imitate conventional gestures (for example, hugging) and actions with objects, to utter greetings ("Hi!") and namelike words, and to pretend to carry out adult activities such as telephoning or mopping the floor (Bretherton, McNew, \& Beeghly-Smith, 1981; Trevarthen \& Hubley, 1978). This is also the period during which the infant shows "social referencing" in seeking out a caregiver's affective expression, relating this to the current situation, and reacting accordingly in feeling as well as action (Campos \& Stenberg, 1981; Feinman, 1982; Feinman \& Lewis, 1983; Klinnert, Campos, Sorce, Emde, \& Svejda, 1983).

This catalogue of new communicative 
and cognitive abilities is far from homogeneous. By requesting things and initiating games, the infant reveals a capacity to relate in various ways to another person's intentions and/or actions; by imitating conventional gestures and other behavior, the infant demonstrates an ability to adopt and execute the actions of another person. Very recently, a highly ingenious visual dishabituation experiment by Gergely, Nadasdy, Csibra, and Biro (in press) yielded confirmatory evidence that 12-month-olds can identify an agent (in this case, a computergenerated circle behaving in humanlike ways) and interpret the agent's actions in relation to its goal. What of the infant's ways of relating to people's attitudes? By showing objects and monitoring the other person's bodily expressive responses, the infant manifests some level of awareness that "showing" may be necessary and potentially sufficient to achieve a special kind of interpersonal coordination and quite possibly, a sense of sharing with another person. If it is the case that, at the end of the first year, an infant is obeying and refusing, or adopting adultlike sounds or gestures to express greetings and farewells (provided, that is, the infants are indeed expressing greetings and farewells, even in restricted contexts), then this seems to imply that the infant is complying with, opposing, and identifying with the perceived attitudes of others. When in circumstances of social referencing, the infant adopts someone else's evaluation of an object or event-for example, avoiding a toy toward which an adult has shown disgust (Hornik, Risenhoover, \& Gunnar, 1987; Walden \& Ogan, 1988) - the infant shows how he or she has a propensity to assume the other person's attitude toward a particular target situated in a shared world.

In each of these cases, it is a moot point whether the infant's "level of awareness" includes a representation (or even more strongly, an understanding or concept) of the other person's attitude, intention, or other mental state. What appears to be necessary and perhaps sufficient, is that the infant registers and interprets the directedness of the attitudes and goal-directed actions that are manifest in others' expressions and behavior. The infant also reacts to and acts upon such attitudes and actions, for example by assuming corresponding attitudes (as in sharing) or by imitating or thwarting others' actions. This implies a motivational and emotional investment in the various forms of interpersonal engagement.

Yet once again, the attitude-versusaction distinction points to a contrast between two potentially dissociable forms of social engagement. On the one hand, there is the mode of intersubjective engagement in which the infant registers and has an emotionally patterned reaction to another person's (subjectively experienced) attitudes. Here the paradigmatic case is an infant's response to another's expressions of affect. For truly intersubjective contact, the infant needs to maintain a focus on the source of the attitudes - that is, the other person - and must not merely use the affect expressed to indicate the potential desirability, danger, or whatever of the objects to which that person is relating. A second mode of engagement may involve the infant's perceiving, reacting to, and sometimes appropriating a person's actions, without a sense of intersubjective connectedness to the other person. After all, a human being can imitate nonhuman animals as well as certain machines, without any interindividual sharing or coordination of mental states.

I intend to highlight the implications of this perspective for our account of the early development of symbolic thought and language. I also provide some justification for the approach by citing some relevant evidence from a recent experimental investigation with autistic individuals.

\section{An Experimental Study With Autistic Individuals}

I summarize selected results from a study by colleagues and myself (Moore, Hobson, \& Lee, 1994), which suggest that in autism we may find a relative dissociation between the ability to perceive people's actions on the 
one hand, and the ability to perceive (and engage with) people's feelings and emotionrelated attitudes on the other.

Groups of 13 autistic and nonautistic retarded participants were pairwise matched for chronological age and verbal mental age as assessed by the British Picture Vocabulary Scale (Dunn, Dunn, \& Whetton, 1982). In fact, we also included a mental agematched group of normal children, but I shall not consider them further except to state that their performance was closely similar to that of the nonautistic control group.

The technique was to present brief videotape sequences of a moving person visible only as points of light emanating from reflective patches attached to the person's limbs and body, a technique pioneered by Johansson (1973). There was an introductory procedure in which subjects were shown a fully visible person who was subsequently seen walking in "point-light" form in darkness, and then reilluminated. All subjects were able to grasp how a person was being represented. The task involved the presentation of separate 5-s sequences of the point-light person enacting gestures of surprise, sadness, fear, anger, and happiness, respectively. For example, the "sad" person walked forward slowly, sighed, sat down on a chair limply, lifted his hands slowly, and put his head in his hands. Participants were told, "You're going to see some bits of film of a person moving. I want you to tell me about this person. Tell me what's happening." We took care to phrase prompts in terms of "what was happening," and made no reference to feelings nor actions. Our prediction was that autistic individuals would differ from control subjects in remarking on the actions, rather than the emotional attitudes, of the person depicted.

Our predictions were borne out by the results. Whereas 10 out of 13 autistic individuals failed to refer to emotional states (whether correctly or incorrectly) on all five presentations of the basic emotions, only one of the nonautistic mentally retarded participants performed in this way, and the majority referred to emotions on at least two occasions. The group difference was not caused by a failure to respond by autistic individuals. On each and every item, all participants of each group made reference to meaningful content in what was depicted, in nearly every case either to emotion or to actions and movements of the arms and legs of the point-light person. Typical responses for the autistic group were "walking and sitting down on a chair" for sad, "standing up and moving backward" for scared, and "walking and jogging and shaking his arms" for angry. Unlike control participants, they attended to (became psychologically engaged with) and remarked on the actions, but not the attitudes, of the point-light person.

The succeeding task was designed to explore the accuracy with which participants were able to name actions and emotional or emotion-related psychological states in point-light displays of a person, when they were asked specific questions in these respects. In this case, the separate 5-s displays involved 10 nonemotional actions (lifting, chopping, hopping, kicking, jumping, pushing, digging, sitting, climbing, and running) and 10 gestures and actions that had emotionally expressive content (the five basic emotions employed in the first experiment, and the states of itchiness, boredom, tiredness, cold, and hurt). The nonemotional actions were presented in one videotape, and the emotion-related states were presented in another, with a counterbalanced order to the presentation of the videotapes. For the "actions" videotape, the experimenter said, "I want you to tell me what the person is doing"; for the "attitudes" videotape, he said, "I want you to tell me what the person is feeling."

At the outset, we had intended to exclude from the analysis of results those items that yielded ceiling or floor effects. This applied to the actions of kicking and jumping, and the emotions of surprise and boredom, respectively. The results on the remaining items were that the nonemotion and emotion conditions were equally difficult for the nonautistic retarded subjects. Moreover, there was not a significant difference 
between autistic and nonautistic subjects on the nonemotion (actions) task. In contrast to this result, the autistic subjects achieved significantly lower scores on the task involving judgements of emotion-related states (following the finding of a significant group-by-condition interaction on ANOVA, an independent $t$ test with a Bonferroni correction yielded $t=4.0, d f=24, p<$ $.005)$. The two groups differed significantly in their abilities to name the point-light displays depicting happiness, fear, sadness, itchiness, and anger, so that the results reflected far-reaching impairments in autistic subjects' ability to recognize attitudes, not merely selective deficits in naming so-called "cognitive" emotions dependent upon beliefs (Baron-Cohen, Spitz, \& Cross, 1993).

In summary, the study yielded evidence for a remarkable specificity in autistic individuals' lesser attentiveness to and impaired discrimination of emotion-related attitudes in the gestures of people, as represented in whole-body, point-light videotape displays. The autistic subjects could recognize certain person-related meanings even in such "abstract" (but ecologically valid) biomechanical representations, but these meanings had to do with actions rather than subjective states. The findings are relevant for accounts of autistic individuals' impairments in understanding as well as perceiving "persons" as beings with their own subjective orientations to the world (e.g., Hobson, 1993). Moreover, autistic children's relative failure to attend to and identify with such attitudes is likely to have far-reaching consequences for their capacity to adopt the attitudes of other people, and thereby to distance themselves from their own "egocentric" attitudes to the world.

\section{Implications for Cognitive and Language Development}

I have been focusing on whether there are separate "action" and "attitude" components to person perception and responsivity. If so, this fact is likely to shed light on the origins of interpersonal understanding (or in modern parlance, "theory of mind"). In previous work, I have stressed the signifi- cance of biologically based interpersonal coordination, and especially affective coordination, for a child's growing understanding that people have their own subjective states of mind (e.g., Hobson, 1990c, 1990b, $1991,1993 b)$. On the other hand, it has remained an open question how far a young child might come to understand personswith-minds on the basis of capacities to perceive and respond to actions, rather than bodily expressed subjective states, manifest in the behavior of others. This distinction is neither clear nor absolute, insofar as the perception and understanding of actions may encompass more than a grasp of goaldirectedness that one could attribute to machines, and might extend to notions about a person's subjectively grounded intentions behind such actions (e.g., Premack, 1991). Nevertheless, as the difference between protodeclarative and protoimperative communication illustrates, this may be a distinction worth pursuing (Camaioni, 1992; Gomez, Sarria, \& Tamarit, 1993; Hobson, 1994).

There are a number of theoretical works that have a bearing upon this issue. For example, Trevarthen (1982) contrasts the interpersonal and practical aims of infants, but he tends to class together the infant's "primary motives for transmission of feelings and purposes between human subjects" (Trevarthen, 1982, p. 85). In an analysis of the Language Acquisition Support System, Bruner (1983) stresses the role of the conventional format, "a routinized and repeated interaction in which an adult and child do things to and with each other" ( $p$. 132, Bruner's italics). In fact, such "doing" includes achieving joint attention as well as joint action, and Bruner is concerned with "referring" as much as he is with "requesting." Bruner claims that the intent to refer, as well as the recognition of that intent in others, is unlearned (Bruner, 1983, pp. 122123). It remains possible, however, that reading a person's intent or goal-directedness is one thing, and understanding the particular goal that is intended, namely the goal of referring or communicating, is another.

Consider once again how an infant may be able to perceive actions with goals, for 
example, reaching for something with the goal of grasping the object, or bringing food to one's mouth with the goal of eating it. It is logically and perhaps psychologically possible to perceive the goal of an action without conceiving of an agent with that goal, or a fortiori, without conceiving of an agent who has the intention to achieve the goal. An individual also might perceive and be inclined to mimic and/or imitate the goal-directed actions of others, and by some admixture of first-person experience of the infant's own goal-directed actions and his/her perception and appropriation of the actions of others, come to some more explicit understanding of what it means for actions to be goal-directed (see Russell, 1994, for thoughtful discussion of agency in early mental development). On the other hand, certain actions and gestures have a very special kind of goal, namely the goal of communicating with someone else. Such communicating may take many forms, of course-making and breaking contact as in greetings and farewells, referring to things, informing and persuading, teasing, repudiating, and so on, and it includes the need to convey that one intends to communicate (Grice, 1957). In previous writings, I have argued that to communicate with someone or to refer for someone entails that the someone is recognized as a person with whom psychological sharing is possible (Hobson, 1993c). This recognition entails that an infant registers (not necessarily conceptualizes) other people's emotional states and reacts to expressions of feeling with coordinated (not necessarily concordant) feelings of his or her own. In other words, an understanding of the goal to communicate requires both an understanding of what it means to intend to do something and an understanding of what it means to align or coordinate one's subjective orientation with that of another person. The latter form of understanding could not arise (so the argument goes) except through experience of person-to-person intersubjective linkage and differentiation, experience that comes by virtue of innate capacities for interpersonal-affective exchange.

Conceptual differentiation between self and other involves much more than the kind of ability present in 3-month-olds who register when they are "out of tune" with someone else. There is something quite different about perceiving and reacting to others' attitudes to oneself, perceiving and reacting to others' attitudes to the world, and conceiving and representing other persons (and oneself) as beings who have subjective attitudes. My thesis is that the following are essential prerequisites for the transition from the early forms of one-to-one primary intersubjectivity to the acquisition of an initial understanding of the nature of self vis-à-vis other persons around 18 months-of-age. First, there is the 9-month-old's capacity to perceive the directedness of other people's attitudes, as manifest in social referencing and protodeclarative communication. Second, there is the business of identifying with other people's attitudes, assuming their subjective orientations, whether covertly or overtly in imitation. (Here the claim is that perceiving the directedness of actions, as well as imitating actions, may draw on some similar psychological mechanisms, but that perceiving and assuming attitudes involves something more.) I take it that these abilities and propensities are givens of human psychology. Now that the infant is in a position to relate to given, visually specified objects and events according to how the infant reacts to the situation and according to another person's attitude to the situation, the infant is in a position to notice that attitudes toward things are different from the things themselves-provided two further conditions are met. The first condition is that the infant must register the difference between his/her own attitudes and attitudes perceived in and sometimes taken from others. The second condition is that the infant needs to adopt an attitude to his/her own attitudes. As Mead (1934) originally suggested, and as Hobson (1990a) and Tomasello (1993) have recently discussed, this latter accomplishment may depend on the infant identifying with the other's attitude to him/herself.

The developmental implications of these processes and events, which occupy the period from approximately 9-18 months or 
so, are far-reaching for cognitive and linguistic as well as social development. I have tried to trace these implications in other writings (especially Hobson, 1993c), and here I shall merely signpost some of the areas in which the child's world has been radically altered by his/her ability not only to assume, but also to become aware of assuming, the attitudes of others toward a shared world. In the domain of interpersonal understanding ("theory of mind"), the child conceptualizes how the child is a "self" among other selves, so that he or she can knowingly accommodate to the attitudes, preferences, and mental states of others in sophisticated role taking and acts of empathy (Hoffman, 1984; Kagan, 1982). In the domain of creative symbolic play, the child's insight into the distinction between "thought" (attitude) and "thing" means that he or she can intentionally transfer attitudes from one object or situation to another, and choose to imbue play materials with novel meanings (Leslie, 1987; Hobson, 1990c). In the domain of language, the child's newfound grasp of the ways in which words are anchored to the particular aspect of meaning-for-persons that a person is intending to express, is constitutive of the ability to comprehend and make predicative utterances. The very possibility of articulating comments about a referred-to object or event arises when the child comes to appreciate the manifold thoughts that can be entertained and communicated (by and to imagined persons in different psychological orientations) in relation to given, shared situations. It is no coincidence that the reference-to-predication shift in language (e.g., Bates, 1993) occurs in conjunction with these other changes around 18 months of age.

Even if these sweeping claims about the basis for the cognitive revolution at approximately 18 months are justified, we must still establish how appropriate it is to give such prominence to infant's abilities to perceive, and propensities to identify with, the attitudes of other people. We seem to have left behind the parallel account of infants perceiving and imitating others' actions. Before addressing this. issue, I need to ac- knowledge Alan Leslie's (in press) theoretical approach, which is closely related to my own thesis and is similarly well-placed to accommodate the evidence from autism described earlier. Leslie attributes an infant's knowledge of agency to three distinct "processing subsystems" concerned with mechanical agency, actional agency, and attitudinal agency. It is this latter distinction between two aspects of the intentional properties of agents with which I have been concerned. The former involves agents acting in pursuit of goals (as represented), and the latter concerns attitudes to the.truth of propositions about states of affairs (in Leslie's terminology; I do not think that invoking the notion of "truth" is appropriate for characterizing the nature of mental state understanding in 1- and 2-year-olds, but let that be). Leslie also anchored pretend play and informative communication in an infant's grasp of attitudinal rather than actional agency.

The critical point about the perception of attitudinal agency (Leslie's terms), or about infants' perception of and engagement with attitudes in increasingly sophisticated and cognitively elaborated forms of intersubjective exchange (my terms), is that here we discern the bases for children's concepts of what it is to be a person with subjectively experienced mental states and psychological orientations to the world. The ability to perceive and imitate actions, even goal-directed actions, might itself lead infants to register correspondences between other people and themselves, and might even anchor an understanding of certain linguistic expressions (see Tomasello \& Barton, in press). It is, however, very difficult to see how this alone could yield an understanding of others as subjects of experience who communicate with each other (for arguments against reasoning by analogy from the self's own experiences, for example, see Hobson, 1991). Without such understanding of subjective mental life, and without a grasp of how the world can fall under different descriptions for different people (and for oneself), creative symbolic functioning and language would be severely compromised.

This returns us to the nature and origins 
of thought and to the quote from Vygotsky (1962) with which I began this article. To put it bluntly, we shall never understand how thought is always "about" something, nor how thought originates in human development, unless we appreciate how thoughts about things are abstracted from attitudes toward things-as-experienced. Or to approach the matter differently, our account of a child's understanding of propositional attitudes - what it means to think or believe or wish that such-and-such is the caseneeds to be an account of how the child comes to recognize that because of the nature of people's attitudes (or what it means to construe things according to meaningsfor-persons), the world and imagined possible worlds can be characterized in various ways that may be thought about, believed, wished for, and so on. If this suggestion is correct, then it follows that the development of specifically human forms of higher cognitive functioning depends on developments in interpersonal relations and interpersonal understanding in the earliest phases of life.

\section{Conclusions}

I have drawn attention to a potentially significant theoretical distinction between a young child's ability to perceive and respond to another person's bodily expressed attitudes and the ability to perceive and respond to another person's actions. Although I have not attempted to map out the developmental implications that follow from drawing this distinction, I hope that the pointers I provided in discussing the roots of protodeclarative gestures and reference, and of symbolic functioning and language, are sufficient to indicate the potential importance of an infant's perception of and engagement with other people's attitudes.

Our experiment with autistic individuals may serve to illustrate the potential value of studies in developmental psychopathology for separating out potentially dissociable facets of psychological functioning. Indeed, the evidence that emerged is in keeping with a theoretical approach to autism suggesting that specific impairments in affectively patterned intersubjective engagement may lie at the source of these children's relative lack of "joint-attention," protodeclarative communication, and symbolic play, and may even account for their specific profile of abnormalities in language and thinking (Hobson, 1993c). I shall not pursue the details of that account here, even though I believe it helps justify what might have seemed unlicensed speculation in some parts of this paper. Instead, I turn the argument around, and reflect on the striking evidence for certain abilities in the autistic individuals we have been testing. Not only could our autistic subjects perceive meaningful point-light Gestalten presented on videotape, but they attended to and named the actions of the people portrayed. This finding may reveal an area of social ability in autism that has considerable practical as well as theoretical significance. We are accustomed to highlighting the marked and characteristic disabilities of people with autism, but many such people also acquire impressive (if patchy) cognitive and linguistic abilities. We need to understand how they achieve what they do, as well as to explain the social and intellectual difficulties they face. Autistic children's abilities to perceive actions might provide a route to understanding something about other people and even people's minds, and may assist their struggle (as it often seems to be) to acquire language and to engage in reflective thought, especially when the impediments to truly intersubjective contact are not too severe. Moreover, as colleagues and myself are currently investigating, the perplexing mixture of imitative abilities and disabilities in autistic children (reviewed in Hobson, 1993c), for example in their relatively better performance in copying goal-directed actions than in mimicking meaningless body movements or bodily expressions of affect, may be explicable in terms of their relative ability to perceive actions vis-à-vis bodily expressed attitudes. Because interpersonal engagement has a strongly motivational component, we may also be led to see why autistic children often fail to react to or imitate certain of the expressive gestures and actions of other peo- 
ple, whereas they appear to notice and sometimes to adopt other kinds of action and even communicative expression. Even more important, we may begin to discern the reasons for their lack of interest and investment in, as well as limited appreciation of, the emotional and cognitive dimensions of human cultural life (Hobson, 1993c; Tomasello, Kruger, \& Ratner, 1993).

This line of reasoning may not be correct in all its particulars, but it exemplifies how theoretical as well as empirical study in the field of development psychopathology may lead to new perspectives on both normal and abnormal psychological functioningin the present case, on specific facets of interpersonal perception and affective engagement that may prove to have great significance for early cognitive as well as social development.

\section{References}

Baron-Cohen, S., Spitz, A., \& Cross, P. (1993). Do children with autism recognise surprise? A research note. Cognition and Emotion, 7, 507-516.

Bates, E. (1979). The emergence of symbols: Ontogeny and phylogeny. In W. A. Collins (Ed.), Children's language and communication, Minnesota symposia on child psychology (Vol. 12, pp. 121-155). Hillsdale, NJ: Erlbaum.

Bates, E. (1993, February). Nature, nurture and language development. Paper presented to the Society for Research in Child Development, New Orleans, LA.

Bates, E., Benigni, L., Bretherton, I., Camaioni, L., \& Volterra, V. (1979). Cognition and communication from nine to thirteen months: Correlational findings. In E. Bates (Ed.), The emergence of symbols: Cognition and communication in infancy (pp. 69140). New York: Plenum.

Bates, E., Camaioni, L., \& Volterra, V. (1975). The acquisition of performatives prior to speech. MerrillPalmer Quarterly, 21, 205-226.

Bertenthal, B. I., Proffitt, D. R., \& Cutting, J. E. (1984). Infant sensitivity to figural coherence in biomechanical motions. Journal of Experimental Child Psychology, 37, 213-230.

Brazelton, T. B., Koslowski, B., \& Main, M. (1974). The origins of reciprocity: The early mother-infant interaction. In M. Lewis \& L. A. Rosenblum (Eds.), The effect of infancy on its caregiver (pp. 49-77). New York: Wiley.

Bretherton, I., McNew, S., \& Beeghly-Smith, M. (1981). Early person knowledge as expressed in gestural and verbal communication: When do infants acquire a "theory of mind"? In M. E. Lamb \& L. R. Sherrod (Eds.), Infant social cognition: Empirical and theoretical considerations (pp. 333-373). Hillsdale, NJ: Erlbaum.

Bruner, J.S. (1983). Child's talk. Oxford: Oxford University Press.

Camaioni, L. (1992). Mind knowledge in infancy: The emergence of intentional communication. Early Development and Parenting, 1, 15-22.

Campos, J. J., \& Stenberg, C. R. (1981). Perception, appraisal and emotion: The onset of social referencing. In M. E. Lamb \& L. R. Sherrod (Eds.), Infant social cognition: Empirical and theoretical considerations (pp. 273-314). Hillsdale, NJ: Erlbaum.

Caron, A. J., Caron, R. F., \& Meyers, R. S. (1982). Abstraction of invariant face expressions in infancy. Child Development, 53, 1008-1015.

Cohn, J. F., \& Tronick, E. (1983). Three-month-old infants' reaction to simulated maternal depression. Child Development, 54, 185-193.

Dunn, L. M., Dunn, L., \& Whetton, C. (1982). British picture vocabulary scale. Windsor: NFER-Nelson.

Feinman, S. (1982). Social referencing in infancy. Merrill-Palmer Quarterly, 28, 445-470.

Feinman, S., \& Lewis, M. (1983). Social referencing at ten months: A second-order effect on infants' responses to strangers. Child Development, 54, 878887.

Field, T. M. (1985). Neonatal perception of people: Maturational and individual differences. In T. M. Field \& N. A. Fox (Eds.), Social perception in infants (pp. 31-52). Norwood, NJ: Ablex.

Field, T. M., Woodson, R., Cohen, D., Greenberg, R., Garcia, R., \& Collins, K. (1983). Discrimination and imitation of facial expressions by term and preterm neonates. Infant Behavior and Development, 6, 485-489.

Field, T. M., Woodson, R., Greenberg, R., \& Cohen, D. (1982). Discrimination and imitation of facial expressions by neonates. Science, 218, 179-181.

Fodor, J. (1980). Methodological solipsism considered as a research strategy in cognitive science. Behavioral and Brain Sciences, 3, 63-109.

Fox, R., \& McDaniel, C. (1982). The perception of biological motion by human infants. Science, 218, 486-487.

Frye, D., Rawling, P., Moore, C., \& Myers, I. (1983). Object-person discrimination and communication at 3 and 10 months. Developmental Psychology, 19, 303-309.

Gergely, G., Nadasdy, Z., Csibra, G., \& Biro, S. (in press). Taking the intentional stance at 12 months of age. Cognition.

Gomez, J.-C., Sarria, E., \& Tamarit, J. (1993). The comparative study of early communication and theories of mind: Ontogeny, phylogeny, and pathology. In S. Baron-Cohen, H. Tager-Flusberg, \& D. Cohen (Eds.), Understanding other minds: Perspectives from autism (pp. 397-426). Oxford: Oxford University Press.

Grice, H. P. (1957). Meaning. Philosophical Review, $66,377-388$.

Haviland, J. M., \& Lelwica, M. (1987). The induced affect response: 10-week-old infants' responses to three emotion expressions. Developmental Psychology, 23, 97-104.

Hobson, R. P. (1989). Beyond cognition: A theory of autism. In G. Dawson (Ed.), Autism: Nature, diag- 
nosis, and treatment (pp. 22-48). New York: Guilford.

Hobson, R. P. (1990a). On the origins of self and the case of autism. Development and Psychopathology, 2, 163-181.

Hobson, R. P. (1990b). Concerning knowledge of mental states. British Journal of Medical Psychology, 63, 199-213.

Hobson, R. P. (1990c). On acquiring knowledge about people and the capacity to pretend: A response to Leslie. Psychological Review, 97, 114-121.

Hobson, R. P. (1991). Against the theory of "Theory of Mind." British Journal of Developmental Psychology, 9, 33-51.

Hobson, R. P. (1993a). Understanding persons: The role of affect. In $S$. Baron-Cohen, $H$. TagerFlusberg, \& D. J. Cohen (Eds.), Understanding other minds: Perspectives from autism (pp. 204227). Oxford: Oxford University Press.

Hobson, R. P. (1993b). The emotional origins of interpersonal understanding. Philosophical Psychology, 6, 227-249.

Hobson, R. P. (1993c). Autism and the development of mind. Hove, Sussex: Erlbaum.

Hobson, R. P. (1994). Perceiving attitudes, conceiving minds. In C. Lewis \& P. Mitchell (Eds.), Origins of an understanding of mind. Hillsdale, NJ: Erlbaum.

Hoffman, M. L. (1984). Interaction of affect and cognition in empathy. In C. E. Izard, J. Kagan, \& R. B. Zajonc (Eds.), Emotions, cognition and behaviour (pp. 101-131). Cambridge: Cambridge University Press.

Hornik, R., Risenhoover, N., \& Gunnar, M. (1987). The effects of maternal positive, neutral and negative affective communications on infant responses to new toys. Child Development, 58, 937-944.

Johansson, G. (1973). Visual perception of biological motion and model for its analysis. Perception and Psychophysics, 14, 201-211.

Kagan, J. (1982). The emergence of self. Journal of Child Psychology and Psychiatry and Allied Disciplines, 23, 363-381.

Kaye, K. (1982). The mental and social life of babies. London: Methuen.

Klinnert, M. D., Campos, J. J., Sorce, J. F., Emde, R. N., \& Svejda, M. (1983). Emotions as behavior regulators: Social referencing in infancy. In $R$. Plutchik \& H. Kellerman (Eds.), Emotion: Theory, research and experience. Vol. 2: Emotions in early development (pp. 57-86). New York: Academic Press.

La Barbera, J. D., Izard, C. E., Vietze, P., \& Parisi, S. A. (1976). Four- and six-month-old infants' visual responses to joy, anger, and neutral expressions. Child Development, 47, 535-538.

Leslie, A. M. (1987). Pretense and representation: The origins of "theory of mind." Psychological Review, 94, 412-426.

Leslie, A. M. (1994). ToMM, ToBy, and agency: Core architecture and domain specificity. In L. Hirschfeld \& S. Gelman (Eds.), Domain specificity in cognition and culture: Mapping the mind (pp. 119148). New York: Cambridge University Press.

Mead, G. H. (1934). Mind, self and society. Chicago and London: University of Chicago Press.

Meltzoff, A. N. (1990). Foundations for developing a concept of self: The role of imitation in relating self to other and the value of social mirroring, social modeling, and self practice in infancy. In D. Cic- chetti \& M. Beeghly (Eds.), The self in transition (pp. 139-164). Chicago: University of Chicago Press.

Meltzoff, A. N., \& Moore, M. K. (1977). Imitation of facial and manual gestures by human neonates. Science, 198, 75-78.

Meltzoff, A. N., \& Moore, M. K. (1983). Newborn infants imitate adult facial gestures. Child Development, 54, 702-709.

Meltzoff, A. N., \& Moore, M. K. (1989). Imitation in newborn infants: Exploring the range of gestures imitated and the underlying mechanisms. Developmental Psychology, 25, 954-962.

Moore, D., Hobson, R. P., \& Lee, A. (1994). Components of person-perception: An investigation with autistic, nonautistic retarded and normal children and adolescents. Manuscript submitted for publication.

Murray, L., \& Trevarthen, C. (1985). Emotional regulation of interactions between two-month-olds and their mothers. In T. M. Field \& N. A. Fox (Eds.), Social perception of infants (pp. 177-197). Norwood, NJ: Ablex.

Premack, D. (1991). The infant's theory of selfpropelled objects. In D. Frye \& C. Moore (Eds.), Children's theories of mind (pp. 39-48). Hillsdale, NJ: Erlbaum.

Russell, J. (1994). Agency and early mental development. In J. Bermudez, A. J. Marcel, \& N. Eilan (Eds.), The body and the self. Cambridge, MA: MIT Press.

Sagi, A., \& Hoffman, M. L. (1976). Empathetic distress in the newborn. Developmental Psychology, $12,175-176$.

Simner, M. L. (1971). Newborns' response to the cry of another infant. Developmental Psychology, 5, 136-150.

Stern, D. (1977). The first relationship: Infant and mother. Glasgow: Fontana/Open Books.

Sylvester-Bradley, B. (1985). Failure to distinguish between people and things in early infancy. British Journal of Developmental Psychology, 3, 281-292.

Tomasello, M. (1993). On the interpersonal origins of self-concept. In U. Neisser (Ed.), The perceived self (pp. 174-184). Cambridge: Cambridge University Press.

Tomasello, M., \& Barton, M. (in press). Learning words in non-ostensive contexts. Developmental Psychology.

Tomasello, M., Kruger, A. C., \& Ratner, H. H. (1993). Cultural learning. Behavioral and Brain Sciences.

Trevarthen, C. (1979). Communication and cooperation in early infancy: A description of primary intersubjectivity. In M. Bullowa (Ed.), Before speech (pp. 321-347). Cambridge: Cambridge University Press.

Trevarthen, C. (1982). The primary motives for cooperative understanding. In G. Butterworth \& P. Light (Eds.), Social cognition (pp. 77-109). Brighton: Harvester.

Trevarthen, C., \& Hubley, P. (1978). Secondary intersubjectivity: Confidence, confiding and acts of meaning in the first year. In A. Lock (Ed.), Action, gesture and symbol: The emergence of language (pp. 183-229). London: Academic Press.

Vygotsky, L. S. (1962). Thought and language. Cambridge, MA: MIT Press.

Walden, T. A., \& Ogan, T. A. (1988). The develop- 
ment of social referencing. Child Development, 59, 1230-1240.

Walker, A. S. (1982). Intermodal perception of expressive behaviors by human infants. Journal of Exper- imental Child Psychology, 33, 514-535.

Young-Browne, G., Rosenfeld, H. M., \& Horowitz, F. D. (1977). Infant discrimination of facial expressions. Child Development, 48, 555-562. 